Hautarzt 2014 · 65:1080

DOI 10.1007/s00105-014-3516-6

Online publiziert: 24. September 2014

(c) Springer-Verlag Berlin Heidelberg 2014

\title{
M. Hundeiker
}

Münster, Deutschland

\section{Ein Bronze-Melanom in Basel}

Das große zentrale Treppenhaus im Kunstmuseum Basel wird beherrscht von einer gewaltigen, fast $2 \mathrm{~m}$ hohen Bronzeplastik: „La grande ombre“ von Auguste Rodin (1840-1917). Das Werk ist von 1880, der Guss der hier zu sehenden Figur (Inv. Nr. P 68) ist erst 1938 erfolgt. Die meisten Menschen gehen rasch daran vorbei. Der Dermatologe ist gewohnt hinzusehen. Er sieht an der linken Wade distal eine Unebenheit. Bei näherer Betrachtung erweist sie sich als bogig begrenzt, beetartig verdickt, mit einem unregelmäßig geformten Knoten an einer Stelle am Rande (• Abb. 1). Eine zufällige Unregelmäßigkeit? Wenn man den oberen Stock erreicht hat, kann man eine zweite Version des gleichen Themas betrachten: „La petite ombre“ (1880; Inv. Nr. Im 1461). Sie hat einen gleichen Befund. Auch ohne jegliche Farbe ist schon allein die Form so charakteristisch, dass man die Diagnose stellen kann: superfiziell spreitendes Melanom.

\section{Korrespondenzadresse}

\section{Prof. Dr. M. Hundeiker}

Immelmannstraße 16, 48157 Münster

max@hundeiker.de

\section{Einhaltung ethischer Richtlinien}

Interessenkonflikt. M. Hundeiker gibt an, dass kein Interessenkonflikt besteht.

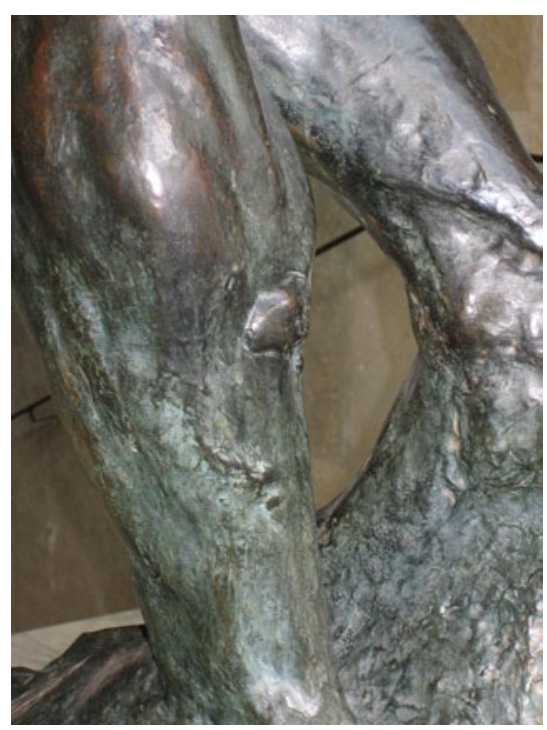

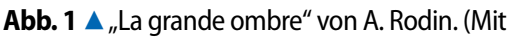
freundl. Genehmigung des Kunstmuseums Basel) 